\title{
Toward a Coherent Framework: A Typology and Conceptualization of CSO Regulatory Regimes
}

\author{
${ }^{1}$ School of Public and Environmental Affairs \& Department of Political Science, Indiana University, Bloomington, IN, USA, E- \\ mail: demattee@indiana.edu.https://orcid.org/0000-0001-7946-7831.
}

\begin{abstract}
:
Scholarship and practitioners interested in civil society organizations (CSOs) around the world have drawn attention to the growing set of laws-both restrictive and permissive- governing CSO activities. To date, however, there have been limited efforts to typologize these regulations which hinders the ability to analyze their emergence and effects. This article seeks to move scholarship toward a coherent framework by first, introducing a broad typology of governance, formation, operations, and resources provisions that allows for a systematic study of CSO laws and policies across contexts; and second, proposing four ideal-types of regulatory regimes, rigid-conservatism, bureaucratic-illiberalism, permissionless-association, and legitimized-pluralism. These regulatory regimes are political institutions that consist of multiple laws and constitutional protections that govern and protect civil society. The article theorizes the effect of each ideal-type regulatory regime on CSOs' organizational ecology. To provide a concrete example, I apply the typology to the case of Kenya to show how its regulatory regime has changed incrementally over time. Methodologically, the article uses an iterative, inductive review and analysis of academic articles, book chapters, and practitioner reports contributing to our understanding of the laws and policies that regulate CSOs, or what I call CSO regulatory regimes.
\end{abstract}

Keywords: civil society, civil society organizations, NGOs, policy, regulations

DOI: $10.1515 / \mathrm{npf}-2018-0011$

\section{Introduction}

Practitioners, policymakers, and scholars are giving increased attention to the regulatory frameworks governing civil society. Simply stated, these regulatory frameworks are multiple laws combining with constitutional protections to create carefully institutionalized regulatory systems that govern the activity of civil society organizations (CSOs), or what I call CSO regulatory regimes. The smallest, elemental units of these regulatory regimes are their provisions. Analysts have studied many aspects of these regulatory regimes. In this article, I review and synthesize existing scholarship to make two original contributions: first, I propose a broad typology of provisions intended to make the systematic study of CSO laws and policies across contexts more possible; and second, I introduce four ideal-types of regulatory regimes and theorize their effects on the CSO organizational ecology. I close by applying the typology to the Kenyan case to show how its regulatory regime has changed over time.

In reviewing a set of carefully selected scholarship, I find researchers rarely consider regulatory regimes as wholly permissive or categorically restrictive. While some scholars discuss restrictive laws that limit foreign support of CSOs or restrict organizations' operational activities, others argue regulatory requirements facilitate the legitimacy and transparency of CSOs and hold them accountable to citizens and local governments. Second, the specific provisions of regulatory regimes exist in four policy subgroups: governance, formation, operations, and resources, which I explain in depth. Third, within each subgroup are provisions from each side of the restrictivepermissive continuum. Combining the second and third points results in a matrix typology of the many types of provisions that regulate CSOs.

The review found analysts approach the study of CSO regulatory regimes differently: many analyze only restrictive provisions while others study broader subgroups; some examine only the adoption of provisions while others discuss only their outcomes. It appears less common to systematically study regulatory regimes in their entirety and over long periods. Such an approach would recognize regulatory regimes as political institutions with multiple dimensions and long histories. Various combinations of provisions create different organizational ecologies, or enabling environments, that to varying degrees either help or hinder the voluntary

Anthony ]. DeMattee is the corresponding author.

(c) BY $\mathbf{B Y} 2019$ Demattee, published by De Gruyter

This work is licensed under the Creative Commons Attribution 4.o Public License. 
sector. Like other political institutions, regulatory regimes are expected to develop incrementally through a long, slow, and muddled process of institutional change.

Alongside the enabling environment exists a second dimension-complexity—that describes the intricacy of the regulatory regime itself. Combining the enabling nature of the regulatory environment with the complexity of the regulatory regime conceptualizes four ideal-types: rigid-conservatism, bureaucratic-illiberalism, permissionless-association, and legitimized-pluralism. ${ }^{1}$ The final section uses the case of Kenya to demonstrate how this conceptualization allows for the systematic study of civil society regulations over time and at different levels of analysis.

\section{Methods}

This review uses a non-random assortment of secondary sources intentionally selected for their diversity in authorship, geographic focus, and methods. I chose sources from a review of literature across a wide range of disciplines, including specialized publications in nonprofit law, policy, and global affairs. The sample expanded until it reached a point of saturation on the types of provisions discussed. Ultimately, it consists of a diverse assortment of book chapters, peer-reviewed articles, and professional reports produced by analysts from around the world (see Appendix for sources). These works examine regulatory regimes in Asia, Africa, Latin America, North America, and Western Europe; and include in-depth case studies, large cross-national statistical analyses, comparative historical analyses, expert legal reviews, and descriptive accounts connecting real-world events to policy changes. While they vary in scope and level of detail, each contributes toward a systematic conceptualization of CSO regulatory regimes.

An inductive approach produced the typology discussed below. A careful reading of these sources identified many types of provisions in use around the world. I copied these provisions directly from the secondary sources and categorized them by type. In total, I inventoried 71 unique provisions discussed by the authors. Next, I used an iterative process to recategorize these provisions until a specific formulation effectively organized all provisions. Once I had organized provisions by type, I rewrote the provisions into a generalizable institutional syntax ${ }^{2}$ and merged these 71 unique provisions into 56 based on the legal requirements they placed on CSOs. This transformation proved a necessary and valuable step. It not only made the number of provisions discussed by analysts manageable but also translated laws from their natural language into institutional statements that allow for comparability across contexts.

A brief note on the terminology used throughout this article. First, regarding organization types: these regulations identify a broad array of legal entities-e. g. cooperative societies, NGOs, resident societies, foreign charities (Maru 2017; Cunningham 2018). These legal forms are subtypes of civil society organizations, which I define as voluntary associations that exist between the family and the state not operated for profit. The organizations are generally legal entities but may also include informal groups. While they are typically private, non-profit-distributing, self-governing entities organized for public benefit; CSOs also include mutual benefit organizations, religious groups, and advocacy organizations.

Second, I discuss various top-down, command-and-control legal instruments. Utmost among them are written constitutions that I consider superior to the laws of a country even though constitutions and legislation are not always as consequential as presumed (Elkins, Ginsburg, and Melton 2009). Laws are written rules coproduced by the legislature and the executive. Constitutions and laws contain numerous written provisions, or what I sometimes refer to as "institutional statements": which through their shared nature describe opportunities and constraints that create expectations about actors' activities by prescribing, permitting, or advising behavior or outcomes (Crawford and Ostrom 2005). Therefore, in nested architecture, numerous provisions comprise laws, and multiple laws combine with constitutional protections ${ }^{3}$ to create regulatory regimes that structure and incentivize CSO behavior. Ultimately, the typology and conceptualization discussed below show different combinations of provisions exist and argues these differences are explanatory factors available as leverage in an analysis.

\section{A Typology of CSO Regulatory Regimes}

It is first necessary to emphasize a characteristic of these provisions: that to varying degrees, each either helps or hinders CSOs. The critical point is not whether a single provision helps or hinders, but the degree to which the entire regulatory regime encourages or discourages voluntary association and facilitates society's trust in the voluntary sector. The coherent framework that I propose classifies and tallies the provisions of regulatory regimes. Admittedly, such an exercise may lose precision and is undoubtedly imperfect. Nevertheless, there is 
a precedent for such a device in the social sciences. One example of this positive/negative classification and tallying is the Polity IV indicator of democratic well-being, which is merely a country's institutionalized autocracy score subtracted from its institutionalized democracy score (Marshall, Gurr, and Jaggers 2017). Similarly, regulatory regimes are an aggregation of restrictive and permissive provisions.

Labeling a provision as either restrictive or permissive can be controversial. One position that focuses on the organization might classify any provision that prescribes CSOs do 'something' as restricting CSOs. This approach would classify provisions requiring that formal organizations register with the government as "restrictive" irrespective of the simplicity of the process or the tax advantages that accompany registration. Alternatively, a position that focuses on the state might classify any provision as "permissive" as long as representative institutions created it. These organization- and state-centric positions may overemphasize certain actors or processes when determining what is restrictive or permissive.

The moderate approach applied here, assumes reasonable enforcement of provisions and then uses theory to predict the effect those provisions have on society and the voluntary sector. Using a standard classification (Anheier 2005), I consider demand-side theories of trust in nonprofits (Hansmann 1980) followed by supplyside theories that explain the emergence of nonprofits (Young 1983; Frumkin 2002). I classify provisions as either restrictive or permissive using a two-step process. First, a provision is permissive if the demand-side theory predicts the provision improves trust, accountability, or resolves "voluntary failures" (Salamon 1987, 38-42). Classification advances to the second stage if there is no clear demand-side prediction. Here, a provision is restrictive if the supply-side theory predicts it limits organizational autonomy or stifles organizational emergence.

Restrictive provisions are those that deteriorate society's trust in CSOs thus decrease demand for such organizations, or they repress and intimidate organizations and their members and thus decrease the supply of CSOs. In the vernacular of transaction cost economics (Williamson 1981), restrictive provisions increase transaction costs and make it more costly to operate and create such organizations (Salamon and Toepler 2000, 7). In extreme instances, these policies legalize corrosive state action such as harassment and seizure of property, impose excessive burdens, restrict the freedom to associate, limit pluralism and stoke intolerance, and remove legal protections and due process.

Permissive provisions are those that protect society and thus increase demand for CSOs, or they create and preserve CSOs and thereby increase the stock of CSOs over time. Permissive provisions facilitate accountability and transparency that reduce transaction costs for users of nonprofit services (Salamon and Toepler 2000, 5). These policies encourage the development of a country's voluntary sector, allow CSOs to self-regulate and appeal regulators' decisions, provide legal rights and protections, permit access to funds and incentivize private donations, and facilitate practices thought to build trust and protect against misconduct by those that seek to abuse the rights and privileges of the legal form. Permissive provisions help to build trust for CSOs among the public and to prevent unscrupulous actors from abusing the legal form for private gain.

Despite the dichotomy presented here, it may be possible to have a flourishing — if not entirely admirablearray of CSOs within a regulatory regime described as restrictive. ${ }^{4}$ Likewise, a de jure permissive regulatory regime is not guaranteed to sow a vibrant civil society that generates positive democratic values among citizens.

\subsection{Elements of the Institutional Context}

Matrix typologies allow for the intersection of multiple mutually-exclusive organizing principles (Gerring 2012). The restrictive-permissive dichotomy is the first of two organizing principles. The second arranges provisions into four subgroups that comprise the institutional context of regulatory regimes. These mutually exclusive categories stipulate how provisions are made and enforced (governance); define the types of CSOs that can exist and the procedures for their emergence (formation); establish if and how a CSO obtains permission to conduct activities (operations); and outlines how to record and report financial and non-financial assets (resources). Complexity is part of the institutional context but is outside the matrix typology because it is not a mutually exclusive type of provision, nor does theory consider it restrictive or permissive. Instead, complexity describes the intricacy of the regulatory regime and interacts with the enabling environment to produce different types of regulatory regimes.

\subsubsection{Governance Provisions}

Governance provisions structure the amendment and enforcement of provisions contained in other subgroups. These provisions create and empower institutional actors such as government agencies, private self-regulators, and dispute resolution forums that affect CSOs externally. Laws that restrict constitutionally protected free- 
doms-such as the right to associate-are governance provisions because they relate to constitutional provisions that supersede legislative laws and policies. In effect, this category is superior to others because governance provisions control the creation, enforcement, and amendment of other regulatory provisions. Table 1 organizes the 12 governance provisions identified in the sample. The endnotes show examples of restrictive and permissive governance provisions ${ }^{5}$ quoted from the studies reviewed.

Table 1: Matrix typology of provisions that comprise CSO regulatory regimes.

\section{Restrictive \\ Governance Subgroup \\ 1. [Government] [must] [create or appoint agency to implement and enforce the law] [at law's commencement] [or else it is negligent in its duties] (14);}

2. [CSOs] [must] [accept restricted freedoms on certain matters] [after law's commencement] [or else face penalty for non-compliance] (10);

3. [Government] [may] [create or empower cabinet minister to make new rules regulating CSOs on certain matters] [after law's commencement] [or else leave the regulatory regime unchanged] (5);

4. [Agency] [may] [publish certain information about a CSO, or seize CSO property and documents] [with or without reasonable cause after law's commencement] [or else choose other tactics to receive information from CSOs] (4);

5. [Government] [may] [use unorthodox process to pass new CSO laws] [after law's commencement] [or else follow normal pathway to change regulatory regime] (3);

6. [Non-state actors] [must not] [create new CSOs] because only the state may do so [or else face penalty for non-compliance] (3).

\section{ormation Subgroup}

1. [CSOs] [must not] [operate as informal, voluntary associations] and instead must register with the government [or else face penalty for non-compliance] (14);

2. [CSOs] [must not] [appeal the registration denial or deregistration order] [after such a decision has been communicated] [or else face penalty for non-compliance] (7);

3. [CSOs] [must] [reregister or otherwise apply for continuation of the organization] [on a certain day, after a fixed duration, or following meaningful changes to the organization] such as renaming the society, amending its constitution, or becoming a branch of another organization [or else face penalty for non-compliance] (7);

4. [CSOs] [must] [identify minimum number of founders or members] [or else the CSO is ineligible for registration or reregistration] (5);

\section{Permissive}

1. [Agency] [must] [explain penalty for particular offenses, or explain a 'general penalty' for offenses where no penalty is expressly provided] [before commencement of the law] [or else it is negligent in its duties] (8);

2. [Government and agency] [must] [create or empower a dispute resolution forum] such as a court [before commencement of the law] [or else it is negligent in its duties] (6);

3. [CSOs] [may] [adopt standards for self-regulation through associations] [after law's commencement] [or else choose not to be self-regulated] (6);

4. [Government and agency] [must] [create or empower self-regulation forum for CSO self-governance] [after law's commencement] [or else it is negligent in its duties] (5);

5. [CSO self-regulator] [must] [create a code of conduct] to license, supervise, or sanction members if such actions are warranted [after law's commencement] [or else use other legal means of self-regulation] (4);

6. [Agency] [must not] [regulate CSOs without oversight] such as an oversight board of CSO participants, a nomination \& approval process, or clear accountability to elected officials [after law's commencement] [or else it is overstepping its authority] (3).

1. [Agency] [must] [follow explicit termination and dissolution provisions] [when attempting to cancel or suspended a CSO] [or else it is negligent in its duties] (14);

2. [Agency] [must] [explain precise legal definitions of CSOs that it regulates] [at law's commencement] [or else it is negligent in its duties] (11);

3. [Agency] [must not] [reject registration for reasons other than those explicitly stated] [after law's commencement] [or else it is overstepping its authority] (9);

4. [Agency] [must not] [make registration unnecessarily complex or burdensome] [after law's commencement] [or else it is overstepping its authority] (8); 
5. [CSOs] [must] [demonstrate minimum capital requirements] such as financial, non-financial, or expertise [or else it is ineligible for registration or reregistration] (5);

6. [CSOs] [must] [have government agency partner] such as a sponsorship or memo of understanding [or else the CSO is ineligible for registration or reregistration] (3);

7. [CSOs] [must] [pay processing/application fee] [in addition to an application that must be completed as prescribed] [or else the registration or reregistration application will not be reviewed] (3).
5. [Agency] [must] [review and make registration decisions within specified time period] [if an application has been submitted as prescribed] [or else it is negligent in its duties] (7);

6. [CSOs] [must] [produce governing document for self-management] such as bylaws minimally prescribed in policy [if they seek to be a formal organization] [or else face penalty for non-compliance] (5);

7. [Agency] [must] [provide written explanation of registration and reregistration decision] such as certificate of approval or justification for refusal [after a CSO has applied as prescribed] [or else it is negligent in its duties] (2).

\section{Operations Subgroup}

1. [CSOs] [must] [obtain government permission, "permits", for individual projects] [after law's commencement] [or else face penalty for non-compliance] (10);

2. [CSOs] [must] [comply with agency's interference regarding external operations or prescribed coordination across multiple CSOs] [when instructions are communicated with or without reasonable cause] [or else face penalty for non-compliance] (10);

3. [CSOs] [must not] [exceed specific threshold of budget spent on overhead] such as a certain percentage of budgets spent on administrative costs [after law's commencement] [or else face penalty for non-compliance] (7);

4. [CSOs] [must not] [engage in specified activities] such as activism [if it receives foreign funds that exceed a threshold] [or else face penalty for non-compliance] (7);

5. [CSOs] [must] [obtain operational approvals-i.e. general licenses or individual permits—from multiple government units] such as multiple agencies, administrative jurisdictions, or a combination of both [after law's commencement] [or else face penalty for non-compliance] (3);

6. [CSOs] [must] [follow prescribed rules regarding internal administrative matters and/or activities] such keeping registry of members, holding membership meetings at minimal internals, or requiring international CSOs to consult local boards [or else face penalty for non-compliance] (3);

7. [CSOs] [must] [surrender operational assets to government] [after a project is completed or CSO is dissolved] [or else face penalty for non-compliance] (1).
1. [CSOs] [must] [produce summary of operations and activities for public access] [after law's commencement] [or else face penalty for non-compliance] (11);

2. [CSOs] [must not] [pursue certain operational activities due to their legal type and irrespective of other matters] such as when the activity is incongruent with the legal type-e.g., public charities shall not endorse political candidates; the organization is unlawful; or the CSO's legal status has been legally revoked [after law's commencement] [or else face penalty for non-compliance] (11);

3. [CSOs] [must] [obtain a license to repeatedly perform a general activity] as opposed to obtaining a permit each time it plans to perform the activity [after law's commencement] [or else face penalty for non-compliance] (9);

4. [Agency] [must] [have reasonable cause and follow explicit rules when conducting inspections of CSOs] such as requesting specific documentation or investigating offenses [after law's commencement] [or else it is overstepping its authority] (8);

5. [CSO] [may] [use foreign funds for certain activities because its legal definition either expressly permits it or does not explicitly prohibit it] [after law's commencement] [or else choose not to accept the funds] (7);

6. [CSO] [may] [conduct activities without notifying local governments] [after law's commencement] [or else notify government or not conduct activities] (5);

7. [Agency] [must not] [hold CSOs to different requirements for staff than other employers] [after law's commencement] [or else it is overstepping its authority] (4). 
1. [CSOs] [must] [acquire one-time approval to receive foreign funding that is separate from formal registration] [after law's commencement] [or else it cannot receive those resources without facing penalty for non-compliance] (10);

2. [CSOs] [must not] [receive more than a specified threshold of foreign funding] such as a fixed value or percentage of its budget [after law's commencement] [or else face penalty for non-compliance] (9);

3. [CSOs] [must] [acquire government approval for each financial transaction or project] [after law's commencement] [or else it cannot receive those resources without facing penalty for non-compliance] (7);

4. [CSOs] [must] [use certain depository institutions] such as government banks [after law's commencement] [or else face penalty for non-compliance] (7);

5. [CSOs] [must] [provide information on its financial matters] such as financing agreements, contracts, or employee salaries [when the regulating agency requests] [or else face penalty for non-compliance] (7);

6. [CSOs] [must not] [receive foreign funding from certain sources] such as foreign governments or private sponsors explicitly stated [after law's commencement] [or else face penalty for non-compliance] (5);

7. [CSOs] [must] [pay taxes on foreign funding] [when similar funding from domestic sources would not be taxed] [or else face penalty for non-compliance] (5);

8. [CSOs] [must not] [receive any foreign funding under any circumstances] [after law's commencement] [or else face penalty for non-compliance] (4).
1. [CSOs] [must] [report their finances for public access] [after law's commencement] [or else face penalty for non-compliance] (15);

2. [Private entities] [may] [take a tax-deduction for supporting certain CSOs according to their legal type] such as donations to 501(c)(3)s but not contributions to political parties [after law's commencement] [or else choose not to take the deduction] (9);

3. [Government] [must] [ensure CSOs enjoy all the rights that accompany their legal type] such as a preferential treatment on property, sales, or payroll taxes [after law's commencement] [or else it is negligent in its duties] (9);

4. [CSOs] [may] [engage in unrelated business activities] such as revenue generation [after law's commencement] [or else choose not to pursue those activities] (4);

5. [CSOs] [may] [engage in local fundraising or related business activities] such as soliciting donations or selling products/services related to their charitable mission [after law's commencement] [or else choose not to pursue those activities] (4);

6. [CSOs] [may] [appeal decisions that disadvantage their positioning on financial and non-financial matters] such as orders regarding fines, taxes, foreign funding, and ownership of property [after such decisions are communicated] [or else accept the decision] (2);

7. [International CSOs] [must not] [crowd-out local CSO from funding opportunities] such as winning grants or not partnering with domestic CSOs [when funding opportunities are announced] [or else face penalty for non-compliance] (1);

8. [CSOs] [must] [pay taxes on unrelated business activities] such as revenue earned on sales of products/services unrelated to their charitable mission [after law's commencement] [or else face penalty for non-compliance] (1).

Note: Table represents a matrix-typology of the provisions that comprise CSO regulatory regimes. Each row is a unique realm of policy provisions, and each column dichotomizes provisions as either restrictive (left) or permissive (right). The number in parentheses represents the number of times a provision was discussed by scholars in a review of twenty-one studies analyzing CSO regulatory regimes (1996-2018). Each provision is written as an institutional statement following the ADICO syntax provided by Crawford and Ostrom (2005). The essential components of the syntax are identified using brackets: [ATTRIBUTES] identify to whom the statement applies, with the default assumption being all members of the group; [DEONTIC] identifies the expectation of behavior identified by the qualifiers 'may' (permitted), 'must' (obliged), and 'must not' (forbidden); [AIM] specifies the particular action or outcome prescribed, or those actions or outcomes that are forbidden; [CONDITIONS] explains when and where the institutional applies with the default assumption being all times and all places; [OR ELSE] assigns consequences for noncompliance. The familiar example requiring American men to register for Selective Service can be written as an institutional statement thusly: [All male U.S. citizens between the ages of 18 and 25] [must] [register for Selective Service within 30 days of their 18-birthday using one of the methods prescribed by the Selective Service System] [at all times and in all places unless they are exempted] [or else face imprisonment, a fine, or both].

\subsubsection{Formation Provisions}

Formation provisions are primarily concerned with the legal status and processes of voluntary associations that choose to incorporate as formalized CSOs. Whether informal associations must incorporate with the gov- 
ernment is also a formation provision. These provisions stipulate the requirements for registration (e. g. membership, financial capital), how the registration process unfolds, and whether registrations expire. As a legal matter, the status of a CSO and the decision to become a formal organization may determine which provisions apply to it (e. g. lobbying, tax-deductible donations). As a political matter, these policies have a legitimizing effect on organizations and failure to secure/renew the proper status might lead to decreased assets from donors and suspicion from citizens. The review suggests 14 formation provisions that include both permissive and restrictive types. ${ }^{6}$

\subsubsection{Operations Provisions}

Operations provisions regulate how CSOs deploy assets in pursuit of their organizational goals. At a high level, these provisions stipulate issue areas and establish what CSOs can or cannot do. Legal definitions and funding sources often define this operational space. For example, American 501(c)(3)s are limited in their ability to lobby, while nonprofit 501(c)(4)s have no such restriction. These provisions also outline whether and how CSOs must receive permission to conduct operations. The highest burden appears to be provisions that require CSOs to obtain a permit to perform specific projects, but less burdensome is the requirement that CSOs obtain a license to perform a general task. These provisions communicate what (if any) reporting CSOs are expected to make available and to whom. Existing literature discusses both restrictive and permissive types ${ }^{7}$ of 14 operations provisions.

\subsubsection{Resources Provisions}

Resources provisions govern the financial and non-financial assets of CSOs. Some studies consider only provisions that regulate if and how CSOs can receive foreign funding, or what (Rutzen 2015) refers to as "philanthropic protectionism." While funding restrictions have been the focus of numerous scholarly studies and reports, the 16 resources provisions include other restrictive and permissive provisions. ${ }^{8}$ They include provisions that prohibit specific legal forms from engaging in fundraising altogether and others that permit CSOs to raise funds through business activities unrelated to their charitable missions. This subgroup includes provisions governing taxable activities, whether a CSO receives a tax-exemption, whether individuals who donate to a CSO receive a tax-deduction, and other similar matters. These provisions also discuss requirements for auditing and financial reporting, ownership of non-financial resources such as property and equipment, and expectations for working with local partners.

Intersecting the restrictive-permissive dichotomy with the four subgroups creates the matrix typology of CSO regulatory regimes (Table 1). The matrix typology includes an equal number of restrictive and permissive provisions in each subgroup and shows the frequency each provision is discussed by the sources reviewed. Each column dichotomizes provisions as either restrictive (left) or permissive (right) and each row is a unique subgroup. Provisions appear as institutional statements with essential components of the institutional syntax identified using brackets. All provisions take the form of "regulative rules" that include all components of the ADICO syntax, which differentiates them from "norms" that lack consequences for noncompliance and "shared strategies" that lack both an expectation of behavior and consequences for noncompliance (Crawford and Ostrom 2005, 140). The values in parentheses represent tallies across the sample and are not indicative of rigor or depth of analysis nor do they measure the prevalence of any provision in the real world. For example, noting Swedish law does not recognize charitable donations as tax-deductible (Salamon and Toepler 1997, 298) is sufficient to qualify a study as having discussed this particular resources provision.

The sources reviewed here have studied many provisions in different context. It is worth noting two understudied topics in the sample: penalties for noncompliance, and the implementation of policy. Penalties are especially relevant because they structure the incentives that CSOs face in their decision-making ((Crawford and Ostrom 2005), 152; (Rowe 1989)). The most discussed provision in the sample, which requires CSOs to submit annual reports of financial flows, carries a penalty for noncompliance that ranges from written warnings and graduated sanctions for repeat offenders, to immediate deregistration of CSOs. Equally important to the research agenda is the topic of implementation and the political factors that affect the state's enforcement of policies and CSOs' compliance with regulations. Perhaps future research will give increased attention to these topics given their importance to understanding how laws and policies affect the voluntary sector and its stakeholders. 


\subsection{Complexity of the Institutional Context}

Complexity, or the combined intricacy of laws and their provisions, is a vital feature of the institutional context of CSO regulatory regimes. Complexity is not included in the typology of provisions because it is not a mutually exclusive type of provision. Instead, complexity describes features of each policy realm and the regulatory regime as a whole. Because regulatory regimes are rarely studied systematically as a whole, there is no clear consensus on how analysts define regulatory regime complexity. I suggest two types of complexity and discuss how each affects the implementation of regulatory regimes.

\subsubsection{Unidimensional Complexity}

Unidimensional descriptions of complexity are directly observable and represent the heft and breadth of the regulatory regime. Multiple sources recognize that CSO laws cumulate over time (Salamon and Toepler 1997, 11; Sidel 2017, 94-95, 98) and that laws from sub-national and national governments simultaneously affect CSOs (Barber and Farwell 2017, 199). This approach acknowledges that new laws matter but also recognizes that new laws seldom repeal and replace entire pre-existing regulatory regimes. One possible way of operationalizing unidimensional-complexity would be to count the actual number of laws and regulations that govern the sector at a single time. None of the analysts in this sample discussed complexity in this way, but multiple studies acknowledged the dynamism of regulatory regimes of laws entering and exiting the system (Kameri-Mbote 2002; Salamon and Toepler 1997; Mayhew 2005; Chikoto-Schultz and Uzochukwu 2016; Breen, Dunn, and Sidel 2017; Maru 2017; Cunningham 2018). Another approach, used by Bloodgood, Tremblay-Boire, and Prakash $(2014,721)$, defines complexity by counting the number of words in the English translation of each particular CSO regulatory regime. These counting-based definitions of complexity might be imperfect, but they are simple and replicable.

Counting the number of provisions that regulate CSOs is another possible definition of unidimensionalcomplexity. This approach also has drawbacks because complexity defined this way is capped at the number of provisions included a priori in a coding protocol. Still another counting-based definition uses the number of legal definitions of CSOs. Research suggests legal definitions structure how different CSOs emerge, what they can and cannot do, and what government agency regulates their activities. Thus, the more legal forms that exist, the more complex the regulatory regimes. (Cunningham 2018)With this unidimensional definition of complexity, the intricacy of the regulatory regime in Kenya that has six different legal statuses is twice as complex as the frameworks in Sudan, Uganda, and Zimbabwe that identify only three (Maru 2017, 42-43, 55, 58; Chikoto-Schultz and Uzochukwu 2016, 151).

\subsubsection{Multidimensional Complexity}

Complexity may also take the form of a multidimensional indicator that combines several unidimensional measures. For example, researchers might define complexity using a discrete variable ranging from $0-3$ that represents registration complexity. Its value equal to the existence of three types of registration actions that increase the complexity of the registration process: (i) register in a multi-stage process $(0 / 1)$; (ii) register in multiple administrative jurisdictions (0/1); (iii) register with multiple government agencies $(0 / 1)$. This measure has three apparent drawbacks. First, there is no clear consensus of what designates the burden threshold. Even guidance from the Handbook on Good Practices for Laws Relating to Non-Governmental Organizations (World Bank 1997, 36) is unclear: good practice suggests "requiring a minimum number of clearly defined documents" and involving "a minimum [degree] of bureaucratic judgment." Another limitation is its inability to describe the intricacy of other subgroups because it is unclear how relevant the registration process is to the complexity of foreign funding (resources provisions) or self-regulation (governance provisions). A final limitation of this indicator is that other analysts may use it to measure the restrictiveness of the registration process.

The careful analysis of national constitutions uses a multidimensional complexity method (Elkins, Ginsburg, and Melton 2009, 84, 103-106) and defines constitutional 'specificity' as a multidimensional measure combining the number of topics covered within constitutions and the amount of detail given to each topic. 'Scope' is the number of topics in the constitution measured as a percentage of all possible topics included in the coding protocol, and 'detail' is simply words per topic-i. e. the length of the constitution (measured in words) divided by the number of topics it contains. This successful application of multidimensional complexity suggests future studies of regulatory regimes can move beyond unidimensional measures of complexity and control for both the 'scope' and 'detail' of the regulatory regimes. 
The above measures of complexity focus inward, on the text of laws themselves, which may be inadequate for some research questions. Policy process research discusses policymaking as incremental changes and nonincremental innovations (for a comprehensive review see Berry and Berry 2014). Innovation is the process that invents original policies, but the combination of internal determinants and external diffusion that predict whether a policy change will be adopted (Berry and Berry 2014; Berry 1990) and both are affected by complexity defined outwardly according to the issue. Early studies of regulatory policy argued complexity exists when generalists and laypersons are unable to apply relevant facts to discussions of an issue-e. g. environment, energy, transportation, and finance (Gormley 1986, 598-599). This definition makes clear that a policy may be 'elaborate' from an administrative standpoint, but this does not qualify as 'complexity.' Positive correlates to this issues-based definition of complexity are believed to be: regulation of natural monopolies, regulation of larger firms, regulation of emerging technology, and the regulation of substances (Gormley 1986, 601-602). Complexity of this type is shown to slow policy diffusion because it increases uncertainty in the minds of generalist-policymakers and slows the learning mechanism of policy adoption (Makse and Volden 2011; Nicholson-Crotty 2009).

This outward, issue-based definition of complexity applies to the typology I propose. 'Complex' operations provisions are those that require expertise such as detailing licensing and permitting requirements for healthcare and environmental CSOs. As another example, 'complex' resources provisions are those regulations beyond the understanding of generalists and laypersons: taxation, international transactions, audits, and other sophisticated financial matters. Analysts interested in the adoption of these CSO provisions should find 'complex' provisions are adopted more slowly. Along with penalties for noncompliance and the implementation of the policies themselves, complexity appears to be one of the least understood dimensions of regulatory regimes.

\section{A Conceptualization of CSO Regulatory Regimes}

In prior sections, I explained how a review of the literature created a mixed typology of CSO regulatory regimes. Then, I identified and evaluated several possible measures of complexity applicable to the study of regulatory regimes. Throughout the above sections, I defined regulatory regimes as political institutions that regulate civil society within sovereign states. They are the amalgam of legal and regulatory policies that states pass, amend, add to, and replace over time. In these closing sections, I conceptualize four ideal-types of regulatory regimes and theorize how each affects CSOs' organizational ecology. My final section applies the typology and conceptualization to the changing regulatory regime of Kenya.

\subsection{Four Ideal-Types of CSO Regulatory Regimes}

Because individual provisions of regulatory regimes are either restrictive or permissive, each policy subgroup and the overall regulatory regime is restrictive or permissive depending on the proportion of provisions present. Restrictive regulatory regimes can be described as closed and hindering because they lack permissive provisions or because they contain far more restrictive provisions than permissive ones. Permissive regimes can be described as open and empowering because they lack restrictive provisions or because they contain many more permissive provisions than restrictive ones. We can only reach this conclusion through the holistic study of provisions from all subgroups and both sides of the restrictive-permissive continuum.

However, studying only the restrictive-permissive continuum may be insufficient because it confines the analysis to a one-dimensional conceptualization. For example, a fully-open regulatory regime $\left(O P E N_{a}\right)$ might exist with elaborate institutional instruments that facilitate legitimacy, accountability, and transparency in the voluntary sector. Another fully-open regulatory regime $\left(O P E N_{z}\right)$, one whose framework is nonexistent, might not only fail to facilitate legitimacy and accountability but also incentivize unscrupulous behavior that generates distrust towards voluntary associations. These two outcomes are unequal, yet analysts cannot differentiate between them without another analytical dimension. By combining the enabling nature of the regulatory environment (restrictive or permissive) with the complexity of the regime results in four ideal-types of CSO regulatory regimes (Figure 1). 


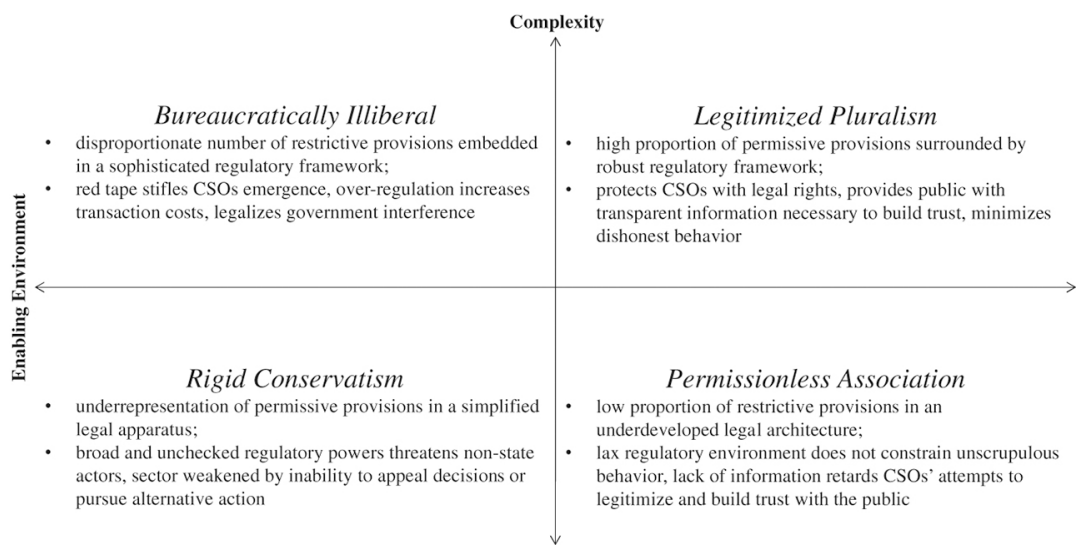

Figure 1: Conceptualizing institutional contexts as ideal types.

Complex regulatory regimes characterize both bureaucratically-illiberal and legitimized-pluralism regulatory regimes, but one is restrictive and the other is permissive. Bureaucratically-illiberal regulatory regimes apply red-tape and erect regulation that increase the transaction costs CSOs must incur to emerge and operate. These regimes may contain laws that legalize government interference, empower government actors with unilateral authority, and prescribe what CSOs must do regarding administrative matters and proscribe what they cannot do regarding operations. In these contexts, the legal and bureaucratic architecture works against the voluntary sector-either intentionally or unintentionally-and limits the availability of these organizations to citizens. If the government regulator has sufficient capacity, politically motivated actors may use bureaucratically-illiberal regulatory regimes to minimize civil society, retard political competition, and dislodge consolidated democracies.

Legitimized-pluralism regulatory regimes protect CSOs with legal rights, provides the public with transparent information necessary to build trust, and minimizes dishonest behavior. These desirable outcomes are possible with a sufficiently developed legal and bureaucratic architecture that supports the voluntary sector and its beneficiaries. Legitimized-pluralism regulatory regimes increase society's demand for CSOs when regulation judiciously culls unlawful actors from the sector and facilitates legitimacy, accountability, and transparency. Transaction costs for CSOs decrease when the government avoids creating unnecessary regulations and enforces existing regulations fairly. This low-cost environment, in turn, increases the supply of CSOs. Therefore, in this ideal-type, the engine of legitimacy and pluralism is the strong rule of law and effective bureaucracy.

Underdeveloped regulatory regimes characterize the rigid-conservatism and permissionless-association regulatory regimes. A restrictive regulatory environment combined with a simplistic regulatory regime produces the rigid-conservatism ideal-type. Here, broad and unchecked regulatory powers threaten non-state actors. For example, CSOs may lack the ability to appeal the regulator's decisions because the simple framework provides no such process; the regulator may arbitrarily decline registrations applications if or when provisions fail to stipulate reasons for rejections; and, self-regulating groups risk deregistration if governance provisions bestow the regulator with enough authority. This ideal-type of regulatory regime introduces uncertainty into the organizational ecology of CSOs because a powerful and unbridled regulator overshadows the voluntary sector.

An open regulatory environment combined with a simple regulatory regime produces the permissionlessassociation ideal-type. In this regulatory regime, a lax regulatory environment may fail to constrain unscrupulous behavior and rent-seeking actors may profit by masquerading as CSOs. Regardless of whether such rentseeking activities are tolerated, ignored, or unnoticed, such profiteering strains society's trust in the voluntary sector and erodes the demand for CSOs broadly. However, this highly permissive regulatory environment permits CSOs to self-organize and choose their instruments to facilitate legitimacy, accountability, and transparency. When done correctly this can (re)build trust in the voluntary sector and stimulate both the demand and supply of CSOs. Therefore, in this ideal-type, the engine of a CSO legitimacy and organizational pluralism is non-state self-regulation.

Several interesting empirical questions emerge from conceptualizing CSO regulatory regimes into four ideal-types. First, research suggests governments are cracking down on CSOs: examples beyond studies already cited include "Why Governments Target Civil Society and What Can Be Done in Response" (Mendelson 2015) and "Explaining State Repression of NGOs" (Chaudhry 2016). Second, the literature indicates that this crack-down is happening primarily through the passage of laws not the removal of policy (Carothers 2006; Gershman and Allen 2006; Carothers and Brechenmacher 2014; Rutzen 2015; Dupuy, Ron, and Prakash 2016). This research suggests that regulatory regimes are changing by becoming more restrictive and more complex and thus more bureaucratically-illiberal. The degree to which this is true is a falsifiable, empirical question that can 
be systematically studied using the typology and ideal-types introduced above. I demonstrate how this can be done later using Kenya's changing regulatory regime.

The ability to apply this conceptualization to multiple levels raises an entirely new set of research questions. Because this conceptualization can bore into a regulatory regime's underlying subgroups, research can assess the sequence, tempo, and distance each subgroup changes and moves through the two-dimensional space. Do regulatory regimes move in gigantic leaps, or do they move incrementally? Does complexity retard adoption as theory predicts? Do the four subgroups move simultaneously in unison, in sequence, or in random directions? Perhaps the single best predictor of knowing where a regulatory regime will stand in the future is understanding where it sits today.

\subsection{Application to the Changing Regulatory Regime of Kenya}

This final section applies my proposed typology and ideal-types to the regulatory regime of Kenya by tracing its development across the conceptual space from 1968 to 2014 . Three laws are central to Kenya's regulatory regime. For over two decades the Societies Act 1968 (commencement February 16th, 1968) empowered the Registrar of Societies to register and regulate CSOs in Kenya. Then the Non-Governmental Organizations Coordination Act, 1990 (commencement December 27th, 1991) added to the regulatory regime and created the Non-Governmental Organizations Co-ordination Board (the "NGO Board") and its executive directorate (the "Bureau") to register and regulate two types of CSOs: international non-governmental organizations, and national non-governmental organizations. Finally, the Public Benefits Organizations Act, 2013 (assent January 14th, 2013; commencement N/A), when enacted, will repeal the NGO Act (section 70), replace the NGO Board and its directorate with a Board of the Authority (section 35), and use the law to replace one self-regulator with another identified as Public Benefit Organizations Regulatory Authority (section 34). These laws have changed Kenya's regulatory regime with their commencement and subsequent amendments ${ }^{9,10,11}$ (see Appendix for specific information).

Coding these primary sources involved coding each law based on the 56 provisions presented in Figure 1. Provisions are coded as 1 if the law contains at least one section addressing the provisions, 0 if the provision is not present in the law, and -1 if the law contains at least one section related to the negation of the provision. Subtracting the total number of restrictive provisions of all existing laws from the total number of permissive provisions of all existing laws locates the regulatory regime along the restrictive-permissive continuum.

Figure 2 shows how new laws and amendments change Kenya's regulatory regime at five distinct periods (identified by letters A-E). Each period contains five vertical lines representing the four subgroups and the regime as a whole. Integers accompany each vertical line for descriptive purposes: integers below and above the lines indicate the number of restrictive (-) and permissive (+) provisions that are present; and integers immediately to the right of the circles and diamonds represent the difference in quantity of restrictive and permissive provisions within subgroups and regimes, respectively. Both restrictive and permissive provisions have comprised the subgroups of the Kenyan regulatory regime since its inception (period A). Closer inspection of the timeline suggests the institutional change of the regulatory regime occurs through the passage of new laws and the amendment of existing ones.

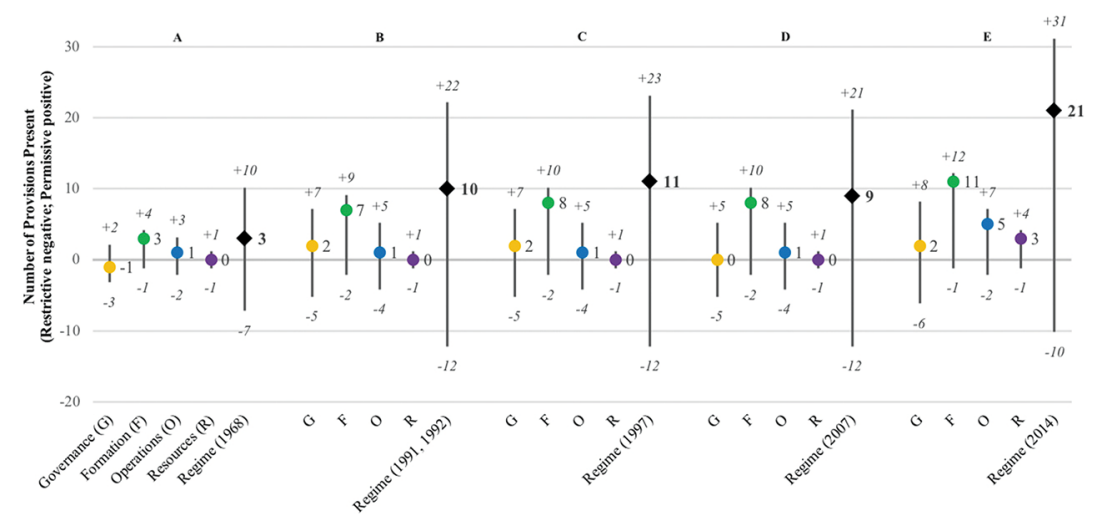

Figure 2: Laws and amendments affecting the institutional context.

The 1968 Kenyan regulatory regime appears slightly permissive as a whole with only the governance subgroup as slightly restrictive. The addition of the NGO Act and its amendments in the early-1990s appear to increase the permissiveness of the regulatory regime. The most significant gains concerning permissiveness occur in the formation and governance subgroups. The 1997 amendment of the Societies Act (period C) required the government regulator to make registration decisions within 120 days (section 4(2)), which added a 
new permissive provision to the formation subgroup and slightly increased the permissiveness of the regulatory regime as a whole. The 2007 amendment made the regime less permissive when it relocated the creation of the code of conduct from the self-regulator to the state regulator (sections 4, 7(h), 24). The biggest jolt to the Kenyan regulatory regime promises to the be the commencement of the PBO Act that repeals the NGO Act and replaces it with numerous permissive provisions across all subgroups.

Figure 3 traces the development of the Kenyan regulatory regime across the conceptual space from 1968 to 2014. Circles represent the four subgroups and the overarching regulatory regime, and shades identify circles belonging to the same point in time. The location of each circle along the horizontal restrictive-permissive continuum corresponds to descriptive integers in Figure 2 (specifically periods A, D, E). The vertical location and size of the circles represent measures of complexity. The $y$-value identifies the scope-complexity of provisions contained in each subgroup and regulatory regimes. It is interpreted directly as the percentage of all provisions from the coding protocol (Table 1) that are present in at least one law at a given period. The distribution of the circles shows approximately $33-75 \%$ of the provisions in the coding protocol are present. Second, the size of each circle represents the detail-complexity of the subgroup or regulatory regime at a given period. It represents the heft of legalese measured as the total number of relevant sections across all existing laws. The coding protocol identified the total number of sections in existing laws relevant to the regulatory regime as increasing over time-41 in 1968, to 72 in 2007, and finally 97 in 2014-and the size of each circle increases accordingly.

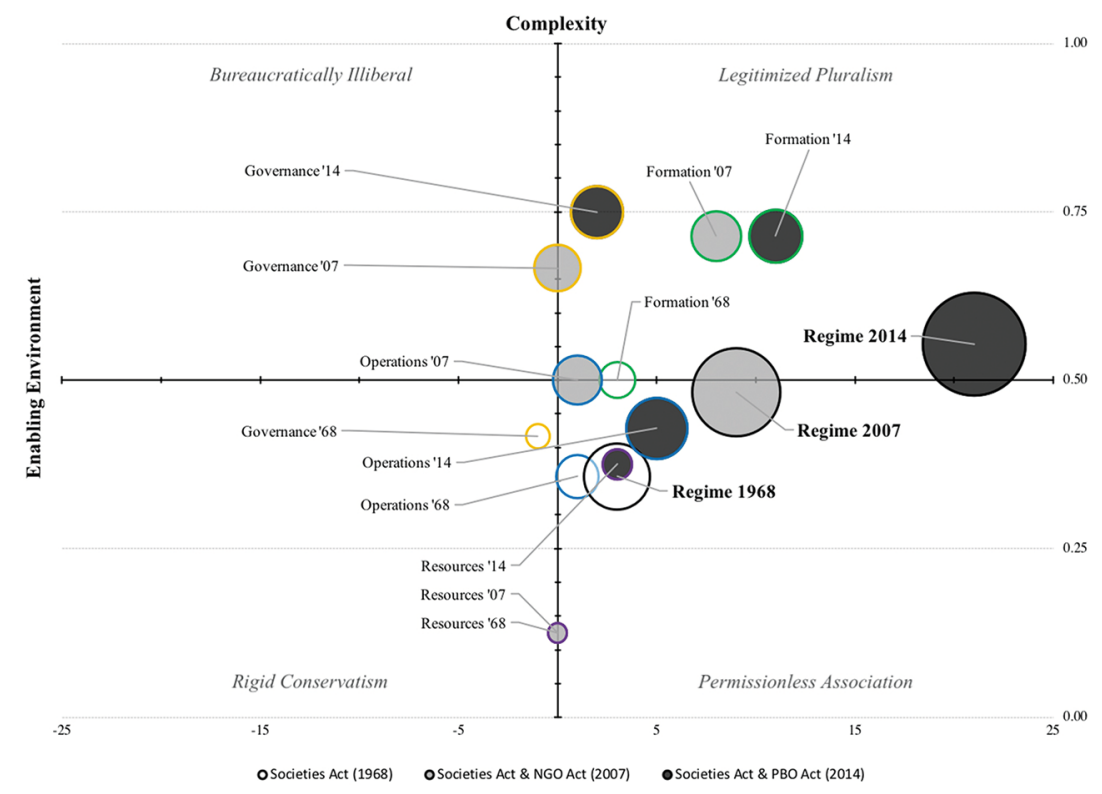

Figure 3: Development of regulatory regimes explained using ideal-types.

Lawmakers moved the Kenyan regulatory regime towards legitimized-pluralism over time through the adoption of new laws and the amendment of current ones. Evidence for this exists because the regulatory regime has become both more permissive and more complex with age. My theory predicts that as regulatory regimes move closer to the legitimized-pluralism, the implementation of the regulatory regime facilitates legitimacy and accountability in the voluntary sector and thereby increase the demand and supply for CSOs. Official information from Kenyan regulators supports this prediction (Registrar of Societies 2018; NGOs Co-Ordination Board 2014). ${ }^{12}$ Government information estimates 4.4 CSOs per ten-thousand Kenyan citizens existed in 1968. In 2007, the figure grew to 8.7, which included 28,149 societies registered with the Registrar of Societies and 5,155 nongovernmental organizations registered with the NGOs Co-Ordination Board. By 2014, the combined number of CSOs-46,344 societies and 9,278 NGOs-meant the Kenyan voluntary sector had approximately 12.1 CSOs per ten-thousand citizens. These CSOs, along with other factors, played a significant role in the late-twentieth and early-twenty-first century Kenyan politics and governance (Mutunga 1999; Brass 2016).

But not all subgroups have followed the same developmental path as the regulatory regime. Figure 3 shows three subgroups moved toward legitimized-pluralism but did so along different trajectories. The governance subgroup increased in complexity without significant increases in permissiveness. The formation subgroup first traveled a steep path towards legitimized-pluralism but has since become more permissive without becoming increasingly complex. The resources subgroup is more complex but only slightly more permissive than it once was. That the resources subgroup is consistently underdeveloped compared to its peers aligns with the policy process literature. The subgroup contains provisions such as taxation, international transactions, and audits that match the issue-based definition of complexity. Greater complexity increases uncertainty for generalist- 
policymakers and slows the learning mechanism of policy adoption; thus, the existing theory predicts this subgroup would be less-developed than the other subgroups with a higher proportion of simpler provisions.

The development of the operations subgroup appears altogether different. The subgroup at first increased in complexity from 1968 to 2007 without a significant increase in permissiveness. The eventual replacement of the NGO Act by the PBO Act would alter the laws and regulations of this subgroup making it more permissive with mixed effects on its complexity. The amended $P B O A c t$, if enacted, would continue to require CSOs file annual reports (sections 15, 31, 42), obtain an operational license (sections 10-11), and undertake certain activities regarding internal administrative matters (sections 8, 11, 25-26, 29-30, 32, 68). But the enactment of the $P B O$ Act alters the permissiveness of the subgroup by introducing new permissive provisions ${ }^{13}$ and omitting provisions that give the regulator explicit authority to directly and indirectly manage and coordinate the work of CSOs (NGO Act section 7(a),(f),(h)). When combined with the provisions of the pre-existing Societies Act, last amended in 1997, the enactment of the amended PBO Act would increase the subgroup's permissiveness, and slightly lower its scope-complexity. If enacted, the act would increase the subgroup's detail-complexity by expanding the number of relevant sections from 23 of 88 total sections in 2007, to 35 of 132 in 2014.

\section{Conclusion}

Recent global affairs and political developments have led governments, practitioners, and social scientists to give renewed attention to the regulatory systems that oversee the activity of civil society organizations (CSOs), or what I call CSO regulatory regimes. While this is a relevant and timely subject, academic research in this area has existed for decades (Brass et al. 2018). Indeed, rigorous academic and practitioner publications have existed on this topic for over two decades (e. g. Salamon and Toepler 1997; World Bank 1997; Ndegwa 1996). The exercise of this article has been to review this vital work, synthesize its findings, and make methodological and theoretical contributions to the study of the CSO regulatory regimes.

The contributions of this article owe a particular debt to the existing work of scholars. Reviewing this research led to the creation of a mixed typology of the provisions that comprise regulatory regimes. The first dimension of the typology organizes provisions as either restrictive or permissive. Restrictive provisions can deteriorate society's trust in CSOs and thus decreases demand for them, or they can repress and intimidate organizations and thus decrease their supply. Permissive provisions, on the other hand, protect society and thus increase demand for CSOs, or create and preserve CSOs and thereby increase their long-run supply. The second dimension of the framework consists of four policy subgroups. These mutually exclusive categories stipulate how provisions get made and enforced (governance); define the types of CSOs that can exist and the procedures for their emergence (formation); establish if and how CSOs obtain permission to conduct activities ions); and outlines how financial and non-financial assets get recorded and reported (resources). A matrix typology organizes the types of provisions analyzed by scholars and presents them in the form of "institutional statements" (Crawford and Ostrom 2005) for generalizability across contexts. Complexity is separate from the matrix typology because it is not a mutually exclusive type of provision. I discussed two types of complexity-unidimensional and multidimensional-and suggested how each can affect the enforcement, compliance, change, and study of regulatory regimes.

By crossing the enabling nature of the regulatory environment with the complexity of the regulatory regime, I proposed four ideal-types of regulatory regimes: rigid-conservatism, bureaucratic-illiberalism, permissionlessassociation, and legitimized-pluralism. When defining these ideal-types, I predict how each affects society and CSOs. At several points, I argue CSO regulatory regimes are best understood political institutions with multiple dimensions and long histories. Thus, the study of the development of regulatory regimes requires multiple approaches including but not limited to institutional change through incremental adjustment (Lindblom 1959), endurance (Weingast 1996), and extended time horizons that account for path-dependency, thresholds, and causal chains (Pierson 1993, 2000, and 2003).

My final section applies the proposed matrix typology and ideal-types to the changing regulatory regime of Kenya. There, I show the typology can be used to systematically and coherently code laws and amendments. The application compared Kenya's regulatory regime to itself from 1968 to 2014 and found the regulatory regime - and most of the subgroups-has become more permissive and increasingly complex. This process of institutional change incrementally moved Kenya's regulatory regime away from the lax regulatory regime of permissionless-association and closer towards legitimized-pluralism where the regulatory regime protects CSOs with legal rights, provides the public with transparent information necessary to build and maintain trust in the sector, and minimizes dishonest behavior from rent-seeking actors masquerading as CSOs. Official information from Kenyan regulatory agencies supports my prediction of a positive relationship between legitimized-pluralism and an expansion in the number of CSOs. 
Of course, the vitality of a country's voluntary sector is not entirely dependent on the laws and policies of the regulatory regime. Laws do not implement themselves and other factors such as political forces, the capacity of state regulators, and individual public administrators responsible for enforcing regulations should not be overlooked. Nevertheless, the regulatory regime is the legal framework that shapes the organizational ecology in which CSOs operate, and its influence is dependent on the rule of law. Unless the rule of law is absent, the regulatory regime must be partially responsible for the health and well-being of CSOs. The degree to which a country's regulatory regime, or the characteristics of its elemental subgroups, affects the size and composition of its voluntary sector is an empirical question that is answerable through the careful and holistic study of these political institutions over time.

\section{Appendix}

\begin{tabular}{|c|c|}
\hline Type & Full Citations of Sources Used in Review Sample \\
\hline Chapter & $\begin{array}{l}\text { Ndegwa, Stephen N. 1996. "NGOs and the State in Kenya." In The Two Faces of Civil Society: NGOs and } \\
\text { Politics in Africa. }\end{array}$ \\
\hline Chapter & $\begin{array}{l}\text { Salamon, Lester M., and Susan L. Q. Flaherty. 1997. “Nonprofit Law: Ten Issues in Search of } \\
\text { Resolution.” In The International Guide to Nonprofit Law. }\end{array}$ \\
\hline Report & $\begin{array}{l}\text { Kameri-Mbote, Patricia. 2002. "The Operational Environment and Constraints for NGOs in Kenya: } \\
\text { Strategies for Good Policy and Practice." }\end{array}$ \\
\hline Report & $\begin{array}{l}\text { Salamon, Lester M., and Stefan Toepler. 2000. “The Influence of the Legal Environment on the } \\
\text { Nonprofit Sector."; reprinted as Salamon, Lester M., and Stefan Toepler. 2012. “The Impact of Law on } \\
\text { Nonprofit Development: A Framework for Analysis." }\end{array}$ \\
\hline Article & $\begin{array}{l}\text { Mayhew, Susannah H. 2005. “Hegemony, Politics and Ideology: The Role of Legislation in } \\
\text { NGO-Government Relations in Asia." The Journal of Development Studies. }\end{array}$ \\
\hline Article & $\begin{array}{l}\text { Gershman, Carl, and Michael Allen. 2006. “The Assault on Democracy Assistance." Journal of } \\
\text { Democracy. }\end{array}$ \\
\hline Report & $\begin{array}{l}\text { Tiwana, Mandeep, and Netsanet Belay. 2010. "Civil Society: The Clampdown is Real - Global Trends } \\
\text { 2009-2010." }\end{array}$ \\
\hline Article & $\begin{array}{l}\text { Christensen, Darin, and Jeremy M Weinstein. 2013. “Defunding Dissent: Restrictions on Aid to } \\
\text { NGOs." Journal of Democracy. }\end{array}$ \\
\hline Report & $\begin{array}{l}\text { Hodenfield, Tor, and Ciana-Marie Pegus. 2013. "Mounting Restrictions on Civil Society: The Gap } \\
\text { Between Rhetoric and Reality." }\end{array}$ \\
\hline Article & $\begin{array}{l}\text { Bloodgood, Elizabeth A., Joannie Tremblay-Boire, and Aseem Prakash. 2014. "National Styles of } \\
\text { NGO Regulation." Nonprofit and Voluntary Sector Quarterly. }\end{array}$ \\
\hline Report & $\begin{array}{l}\text { Carothers, Thomas, and Saskia Brechenmacher. 2014. "Closing Space: Democracy and Human } \\
\text { Rights Support Under Fire." }\end{array}$ \\
\hline Article & $\begin{array}{l}\text { Rutzen, Douglas. 2015. "Aid Barriers and the Rise of Philanthropic Protectionism." International } \\
\text { Journal of Not-for-Profit Law. }\end{array}$ \\
\hline Report & $\begin{array}{l}\text { Wolff, Jonas, and Annika E. Poppe. 2015. "From Closing Space to Contested Spaces: Re-assessing } \\
\text { Current Conflicts over International Civil Society Support." }\end{array}$ \\
\hline Article & $\begin{array}{l}\text { Dupuy, Kendra, James Ron, and Aseem Prakash. 2016. "Hands Off My Regime! Governments' } \\
\text { Restrictions on Foreign Aid to Non-Governmental Organizations in Poor and Middle-Income } \\
\text { Countries." World Development. }\end{array}$ \\
\hline Article & $\begin{array}{l}\text { Chikoto-Schultz, Grace, and Kelechi Uzochukwu. 2016. “Governing Civil Society in Nigeria and } \\
\text { Zimbabwe: A Question of Policy Process and Non-State Actors' Involvement." Nonprofit Policy Forum. }\end{array}$ \\
\hline Chapter & $\begin{array}{l}\text { Appe, Susan, and Marcelo Marchesini da Costa. 2017. "Waves of Nonprofit Regulation and } \\
\text { Self-Regulation in Latin America: Evidence and Trends from Brazil and Ecuador." In Regulatory } \\
\text { Waves: Comparative Perspectives on State Regulation and Self-Regulation Policies in the Nonprofit Sector, ed. } \\
\text { O. B. Breen, A. Dunn and M. Sidel. }\end{array}$ \\
\hline Chapter & $\begin{array}{l}\text { Barber, Putnam, and Megan M. Farwell. 2017. “The Relationships between State and Nonstate } \\
\text { Interventions in Charitable Solicitation Law in the United States.” In Regulatory Waves: Comparative } \\
\text { Perspectives on State Regulation and Self-Regulation Policies in the Nonprofit Sector, ed. O. B. Breen, A. } \\
\text { Dunn and M. Sidel. }\end{array}$ \\
\hline Chapter & $\begin{array}{l}\text { Gugerty, Mary Kay. 2017. “Shifting Patterns of State Regulation and NGO Self-Regulation in } \\
\text { Sub-Saharan Africa." In Regulatory Waves: Comparative Perspectives on State Regulation and } \\
\text { Self-Regulation Policies in the Nonprofit Sector, ed. O. B. Breen, A. Dunn and M. Sidel. }\end{array}$ \\
\hline Chapter & $\begin{array}{l}\text { Sidel, Mark. 2017. "State Regulation and the Emergence of Self-Regulation in the Chinese and } \\
\text { Vietnamese Nonprofit and Philanthropic Sectors." In Regulatory Waves: Comparative Perspectives on } \\
\text { State Regulation and Self-Regulation Policies in the Nonprofit Sector, ed. O. B. Breen, A. Dunn and M. } \\
\text { Sidel. }\end{array}$ \\
\hline
\end{tabular}


Report Maru, Mehari Taddele. 2017. “Legal Frameworks Governing Non-Governmental Organizations in the Horn of Africa."

Chapter Cunningham, Andrew. 2018. “Law as Discourse: The Case of Ethiopia.” In International Humanitarian NGOs and State Relations: Politics, Principles and Identity.

\section{Notes}

1 Ideal-types may not have a real-life empirical referent (Gerring 2012). The systematic study of regulatory regimes will show the degree to which these ideal-types approximate observed reality.

2 For a comprehensive explanation of institutional (or ADICO) syntax read "A Grammar of Institutions" by Sue Crawford and Elinor Ostrom in Understanding Institutional Diversity (Crawford and Ostrom 2005). The five components of the syntax are: (A) attribute, identifies to whom the institutional statement applies, and if no attributes are named then the default assumption is all members of the group; (D) deontic, identifies the expectation of behavior identified by the qualifiers 'may' (permitted), 'must' (obliged), and 'must not' (forbidden); (I) aim, specifies the particular action or outcome prescribed, or those actions or outcomes that are forbidden; (C) conditions, explains when and where the institutional statement applies, and if no conditions are stated then the default assumption is all times and all places; (O) or else, assigns consequences for noncompliance. Please correspond with the author for a list of citations supporting each institutional statement.

3 My appreciation to the reviewers who rightly explain constitutional protections both guarantee freedoms and also set limits on governmental practices.

4 My appreciation to the reviewers for this comment.

5 Governance Examples: Restrictive "[The Ecuadorian Presidential Executive Decree No. 982 (2008)] Registry of Civil Society Organizations (RUOSC) was a first attempt by the Ecuadorian government to standardize and centralize information on nonprofit organization and was woven into the process of an organization's legal formation" (Appe and Marchesini Da Costa 2017, 166); Permissive "[Uganda's NonGovernmental Organizations Act (2016)] introduced [CSOs'] right to appeal to the District Non-Governmental Monitoring Committee, the [National Bureau for NGOs], or the Adjudication Committee. In addition, an aggrieved person may invoke Article 42 of the 1995 Constitution which guarantees the right to be treated fairly and justly and the right to apply to a court of law in respect of any administrative decision taken against that person" (Maru 2017, 61).

6 Formation Examples: Restrictive "Eritrea, Proclamation No. 145/2005 requires that local CSOs engaged in relief and/or rehabilitation work must have 'at their disposal in Eritrea one million US dollars or its equivalent in convertible currency.' This amount is approximately 15,000 average monthly per capita GDP in Eritrea" (Rutzen 2015, 17); Permissive "[CSOs in Nigeria] must be registered or incorporated under the Companies and Allied Matters Act (CAMA Act) of 1990, if they wish to enjoy the benefits of having a legal personality, or the limited tax advantages that may be available to them ... if a CSO's registration request is denied, it can challenge this decision with the Corporate Affairs Commission (CAC)" (Chikoto-Schultz and Uzochukwu 2016, 148).

7 Operations Examples: Restrictive "[Restrictive policies] increase the discretionary supervisory power of government authorities and enable an arbitrary interference in the internal affairs of organizations, [and] restrictions that concern certain 'sensitive' activities (for instance, political activities, or human rights advocacy)" (Wolff and Poppe 2015, 6); Permissive "Cambodia appears to have no explicit [project] approval procedure other than the initial approval of the activity field of [CSOs] at registration and the requirement to submit annual reports" (Mayhew 2005, 741).

8 Resources Examples: Restrictive "In 2008 Jordan enacted a new Law of Societies that requires any NGO seeking to receive foreign funding to obtain approval from the Jordanian cabinet and inform officials of the funding source, amount, and intended purpose ... The Venezuelan National Assembly in December 2010 passed the Law for the Defense of Political Sovereignty and National Self-Determination, which explicitly prohibits NGOs that 'defend political rights' or 'monitor the performance of public bodies' from receiving any income from foreign sources" (Carothers and Brechenmacher 2014, 8); Permissive "Explicit [financial] transparency requirements can provide additional assurance that organizations are operating in a way that is consistent with public expectations" (Salamon and Toepler 2000, 6).

9 The Public Benefits Organizations Act, (2013) was amended in December 2014 and added three subsections regarding the classification of CSOs by the government regulator (section $6(4 \mathrm{~A}-\mathrm{C})$ ).

10 The Societies Act 1968 was amended in November 1997 in several permissive ways: it was now forced to make registration decisions within a specified time (section 4(2)); it drastically reduced penalties for noncompliance (sections 5-6) without increasing the general penalty of the law to compensate for three decades of inflation (section 42); it raised the threshold that allows the Registrar of Societies to conduct inspections or compel CSO action (sections 11-12); and it strengthened the appeal and dispute resolution processes by including the judiciary (sections 15, 18).

11 The Non-Governmental Organizations Co-ordination Act, 1990 was originally passed in January 1991 and quickly amended in December 1991, again in October 1992, and most recently in October 2007. Each amendment process had mixed effects on the regulatory regime. On restrictive matters, the amendments empowered the NGO Board to prescribe terms and conditions to CSO registrations (section 12(3)); removed the ability to "suspend" CSOs for certain offenses leaving only a "deregistration" penalty (section16); and in 2007, moved the responsibility of crafting a code of conduct away from the self-regulator and into the government agency (sections $4,7(\mathrm{~h}), 24)$. On permissive matters, amendments strengthened oversight of the government regulator by including civil society more representatives (section 4 ); strengthened the appeal and dispute resolution processes by including the judiciary (sections 19,34); and in 2007, the process decreased the number of government appointees in the oversight role (section 4(1)(b)).

12 Kenyan population estimates sourced from the World Bank Databank—series (SP.POP.TOTL)—and represent all residents regardless of legal status or citizenship using midyear estimates: 1968, 10.5 million; 2007, 38.1 million; 2014, 46.0 million. http://databank.worldbank.org/

13 The $P B O$ Act allows for the distribution of operational resources to other CSOs rather than government agents (section 62), relies on legal definitions to define the operational boundaries of CSOs (section 66), and limits the regulator's authority to institute inquiries (sections 42 , 63).

\section{References}


Appe, Susan, and Marcelo Marchesini Da Costa. 2017. “Waves of Nonprofit Regulation and Self-Regulation in Latin America: Evidence and Trends from Brazil and Ecuador." In Regulatory Waves: Comparative Perspectives on State Regulation and Self-Regulation Policies in the Nonprofit Sector, edited by Oonagh B. Breen, Alison Dunn, and Mark Sidel, 154-75. Cambridge: Cambridge University Press.

Barber, Putnam, and Megan M. Farwell. 2017. "The Relationships between State and Nonstate Interventions in Charitable Solicitation Law in the United States." In Regulatory Waves: Comparative Perspectives on State Regulation and Self-Regulation Policies in the Nonprofit Sector, edited by Oonagh B. Breen, Alison Dunn, and Mark Sidel, 199-220. Cambridge: Cambridge University Press.

Berry, Frances Stokes, and William D. Berry. 2014. "Innovations and Diffusion Models in Policy Research." In Theories of the Policy Process, edited by Paul A. Sabatier, and Christopher M. Weible, 307-62. New York: Westview Press.

Berry, William D. 1990. “The Confusing Case of Budgetary Incrementalism: Too Many Meanings for a Single Concept." The Journal of Politics 52 (1): 167-96.10.2307/2131424.

Bloodgood, Elizabeth A., Joannie Tremblay-Boire, and Aseem Prakash. 2014. "National Styles of NCO Regulation." Nonprofit and Voluntary Sector Quarterly 43 (4): 716-36. 10.1177/0899764013481111.

Brass, Jennifer N. 2016. Allies or Adversaries? NCOs and the State in Africa. Cambridge: Cambridge University Press.

Brass, Jennifer N., Wesley Longhofer, Rachel S. Robinson, and Allison Schnable. 2018. “NCOs and International Development: A Review of Thirty-Five Years of Scholarship." World Development 112: 136-49. https://doi.org/10.1016/j.worlddev.2018.07.016.

Breen, Oonagh B., Alison Dunn, and Mark Sidel, eds. 2017. Regulatory Waves: Comparative Perspectives on State Regulation and Self-Regulation Policies in the Nonprofit Sector. Cambridge: Cambridge University Press.

Carothers, Thomas. 2006. “The Backlash Against Democracy Promotion." Foreign Affairs 85 (2): 55-68.

Carothers, Thomas, and Saskia Brechenmacher. 2014. Closing Space: Democracy and Human Rights Support under Fire. Washington, DC: Carnegie Endowment for International Peace.

Chaudhry, Suparna 2016. “The Assault on Democracy Assistance: Explaining State Repression of NCOs.” Ph.D., Political Science, Yale University (Dissertation/thesis number 10583219).

Chikoto-Schultz, Grace, and Kelechi Uzochukwu. 2016. "Coverning Civil Society in Nigeria and Zimbabwe: A Question of Policy Process and Non-State Actors' Involvement." Nonprofit Policy Forum 7 (2): 137. 10.1515/npf-2015-0051.

Christensen, Darin, and Jeremy M Weinstein. 2013. "Defunding Dissent: Restrictions on Aid to NCOs." Journal of Democracy 24 (2): 77-91.

Crawford, Sue, and Elinor Ostrom. 2005. "A Grammar of Institutions." In Understanding Institutional Diversity, edited by Elinor Ostrom, 13774. Princeton: Princeton University Press.

Cunningham, Andrew. 2018. "Law as Discourse: The Case of Ethiopia." In International Humanitarian NGOs and State Relations: Politics, Principles and Identity. London: Routledge.

Dupuy, Kendra, and Aseem Prakash. 2017. “Do Donors Reduce Bilateral Aid to Countries with Restrictive NCO Laws? A Panel Study, 19932012." Nonprofit and Voluntary Sector Quarterly 47 (1): 89-106. 10.1177/0899764017737384.

Dupuy, Kendra, James Ron, and Aseem Prakash. 2016. "Hands off My Regime! Covernments' Restrictions on Foreign Aid to NonGovernmental Organizations in Poor and Middle-Income Countries." World Development 84: 299-311. 10.1016/j.worlddev.2016.02.001.

Elkins, Zachary, Tom Ginsburg, and James Melton. 2009. The Endurance of National Constitutions. Cambridge: Cambridge University Press.

Frumkin, Peter. 2002. On Being Nonprofit: A Conceptual and Policy Primer. Cambridge: Harvard University Press.

Gerring, John. 2012. “Descriptive Arguments." In Social Science Methodology: A Unified Framework, 141-54. Cambridge: Cambridge University Press.

Gershman, Carl, and Michael Allen. 2006. "The Assault on Democracy Assistance." Journal of Democracy 17 (2): 36-51.

Cormley, William T. 1986. "Regulatory Issue Networks in a Federal System." Polity 18 (4): 595-620.

Gugerty, Mary Kay. 2017. "Shifting Patterns of State Regulation and NCO Self-Regulation in Sub-Saharan Africa." In Regulatory Waves: Comparative Perspectives on State Regulation and Self-Regulation Policies in the Nonprofit Sector, edited by Oonagh B. Breen, Alison Dunn, and Mark Sidel, 69-91. Cambridge: Cambridge University Press.

Hansmann, Henry. 1980. “The Role of Nonprofit Enterprise.” The Yale Law Journal 89: 835-901.

Hodenfield, Tor, and Ciana-Marie Pegus. 2013. Mounting Restrictions on Civil Society: The Gap between Rhetoric and Reality. Washington, D.C.: CIVICUS: World Alliance for Citizen Participation.

Kameri-Mbote, Patricia. 2002. The Operational Environment and Constraints for NCOs in Kenya: Strategies for Cood Policy and Practice. Ceneva, Switzerland: International Environmental Law Research Centre.

Lindblom, Charles E. 1959. “The Science of 'Muddling Through'." Public Administration Review 19 (2): 79-88.

Makse, Todd, and Craig Volden. 2011. "The Role of Policy Attributes in the Diffusion of Innovations." The Journal of Politics 73 (1): 108-24. $10.1017 / \mathrm{s} 0022381610000903$

Marshall, Monty G., Ted Robert Gurr, and Keith Jaggers. 2017. Polity IV Project: Political Regime Characteristics and Transitions, 1800-2016: Center for Systemic Peace. www.systemicpeace.org.

Maru, Mehari Taddele. 2017. Legal Frameworks Governing Non-Covernmental Organizations in the Horn of Africa. Kampala, Uganda: Al Khatim Adlan Center for Enlightenment and Human Development (KACE).

Mayhew, Susannah H. 2005. "Hegemony, Politics and Ideology: The Role of Legislation in NCO-Government Relations in Asia." The Journal of Development Studies 41 (5): 727-58.10.1080/00220380500145263.

Mendelson, Sarah E. 2015. Why Governments Target Civil Society and What Can Be Done in Response: A New Agenda. Washington, D.C.: Center for Strategic \& International Studies.

Mutunga, Willy. 1999. Constitution-Making from the Middle: Civil Society and Transition Politics in Kenya, 1992-1997, Series on Constitution Making in Kenya. Nairobi, Kenya: SAREAT.

Ndegwa, Stephen N. 1996. "NCOs and the State in Kenya." In The Two Faces of Civil Society: NCOs and Politics in Africa, 31-54. West Hartford, CT: Kumarian Press.

NGOs Co-Ordination Board. 2014. Annual NCO Sector Report for the Financial Year 2013-2014. Nairobi, Kenya: Ministry of Devolution and Planning. 
Nicholson-Crotty, Sean. 2009. “The Politics of Diffusion: Public Policy in the American States.” The Journal of Politics 71 (1): $192-205$. $10.1017 /$ s0022381608090129.

Pierson, Paul. 1993. “When Effect Becomes Cause: Policy Feedback and Political Change.” World Politics 45 (4): 595-628. 10.2307/2950710.

Pierson, Paul. 2000. "Increasing Returns, Path Dependence, and the Study of Politics." The American Political Science Review 94 (2): 251-67. $10.2307 / 2586011$.

Pierson, Paul. 2003. “Big, Slow-Moving, and ... Invisible: Macrosocial Processes in the Study of Comparative Politics." In Comparative Historical Analysis in the Social Sciences, edited by James Mahoney, and Dietrich Rueschemeyer, 177-207. Cambridge: Cambridge University Press.

Public Benefits Organizations Act, 2013. No.18 of 2013.

Registrar of Societies. 2018. Registry of Societies. Nairobi, Kenya: Office of the Attorney Ceneral and Department of Justice.

Rowe, Nicholas. 1989. Rules and Institutions. Ann Arbor: University of Michigan Press.

Rutzen, Douglas. 2015. “Aid Barriers and the Rise of Philanthropic Protectionism." International Journal of Not-for-Profit Law 17 (1): 1-42.

Salamon, Lester M. 1987. “Of Market Failure, Voluntary Failure, and Third-Party Covernment: Toward a Theory of Covernment-Nonprofit Relations in the Modern Welfare State." Nonprofit and Voluntary Sector Quarterly 16 (1-2): 29-49. 10.1177/089976408701600104.

Salamon, Lester M., and Susan L. Q. Flaherty. 1997. “Nonprofit Law: Ten Issues in Search of Resolution.” In The International Cuide to Nonprofit Law, edited by Lester M. Salamon, and Stefan Toepler, 8-42. New York: John Wiley \& Sons, Inc.

Salamon, Lester M., and Stefan Toepler. 1997. The International Cuide to Nonprofit Law. New York: John Wiley \& Sons, Inc.

Salamon, Lester M., and Stefan Toepler. 2000. "Title." Center for Civil Society Studies Working Paper Series, Baltimore.

Salamon, Lester M., and Stefan Toepler. 2012. "The Impact of Law on Nonprofit Development: A Framework for Analysis." In Met Recht Betrokken, edited by C. Overes, and W. van Ween, 276-84. Amsterdam: Kluwe.

Security Laws (Amendment) Act, 2014. No.19 of 2014.

Sidel, Mark. 2017. "State Regulation and the Emergence of Self-Regulation in the Chinese and Vietnamese Nonprofit and Philanthropic Sectors." In Regulatory Waves: Comparative Perspectives on State Regulation and Self-Regulation Policies in the Nonprofit Sector, edited by Oonagh

B. Breen, Alison Dunn, and Mark Sidel, 92-112. Cambridge: Cambridge University Press.

Statue Law (Repeal and Miscellaneous Amendments) Act, 19991. No.14 of 1991.

Statute Law (Miscellaneous Amendments) Act, 1992. No.11 of 1992.

Statute Law (Miscellaneous Amendments) Act, 2007. No.7 of 2007.

Statute Law (Repeals and Miscellaneous Amendments) Act, 1997. No.10 of 1997.

Tiwana, Mandeep, and Netsanet Belay. 2010. Civil Society: The Clampdown Is Real - Clobal Trends 2009-2010. Washington, D.C.: CIVICUS: World Alliance for Citizen Participation.

Weingast, Barry R. 1996. “Political Institutions: Rational Choice Perspectives." In A New Handbook of Political Science, edited by Robert E. Goodin, and Hans-Dieter Klingemann, 167-90. Oxford: Oxford University Press.

Williamson, Oliver E. 1981. “The Economics of Organization: The Transaction Cost Approach.” American Journal of Sociology 87 (3): 548-77.

Wolff, Jonas, and Annika E. Poppe. 2015. From Closing Space to Contested Spaces: Re-Assessing Current Conflicts over International Civil Society Support. Frankfurt: Peace Research Institute Frankfurt (PRIF).

World Bank. 1997. Handbook on Cood Practices for Laws Relating to Non-Covernmental Organizations. Washington, D.C.: World Bank.

Young, Dennis R. 1983. If Not for Profit, for What? A Behavioural Theory of the Nonprofit Sector Based on Entrepreneurship. Lexington: Lexington Books. 